\title{
Pain management in eldercare employees - the role of managers in addressing musculoskeletal pain and pain-related sickness absence
}

\author{
Charlotte Diana Nørregaard Rasmussen ${ }^{*}$, Jodi Oakman², Kristina Karstad ${ }^{1}$, Reiner Rugulies 1,3,4, \\ Andreas Holtermann ${ }^{1}$ and Matthew Leigh Stevens ${ }^{1}$
}

\begin{abstract}
Purpose: Managers'knowledge and behaviors in addressing musculoskeletal pain and sickness absence is not well understood. We investigated the association between managers' knowledge and behaviours in relation to employees' pain and their future risk of musculoskeletal pain and associated sickness absence.

Methods: The prospective study included 535 eldercare employees, and 42 managers from 20 nursing homes. Managers' self-reported knowledge and behaviors in relation to employees' pain were grouped using Principal Components Analysis. Eldercare employees reported pain-related sickness absence, and number of days with musculoskeletal pain repeatedly over 1 year. We investigated associations using mixed-effects regression models.

Results: We identified four types of managers' knowledge and behaviors: 1) Pain-prevention (actions for prevention of employee pain), 2) Pain-management (actions to assist employees manage pain), 3) Pain-entitlements (communicating entitlements to employees with pain), and 4) Pain-accommodations (ability to facilitate workplace accommodations for employees with pain). The employees of managers with higher scores on knowledge of pain-entitlements reported fewer days of pain-related sickness absence $(\beta=-0.62 ; 95 \% \mathrm{Cl}[-1.14 ;-0.10])$. The employees of managers with higher scores on pain-management were more likely to report low back pain $(\beta=0.57 ; 95 \% \mathrm{Cl}[0.02 ; 1.11])$. We found several key associations between the knowledge and behaviors measures and pain-related sickness absence (interactions).

Conclusion: Managers' knowledge and behaviors in relation to employees' pain were associated with employees' future musculoskeletal pain and sickness absence. The relationships are complex, suggesting that a multifaceted approach is needed to ensure that managers are adequately informed on how to manage and accommodate employees with musculoskeletal pain to reduce sickness absence.
\end{abstract}

*Correspondence: cnr@nfa.dk

${ }^{1}$ National Research Centre for the Working Environment, Copenhagen, Denmark

Full list of author information is available at the end of the article

\begin{abstract}
Introduction
The recruitment and retention of employees for the eldercare sector are significant challenges across the globe and urgently require attention to manage the increased need for services due to an ageing population [1]. In Denmark, sickness absence $[2,3]$ and early retirement have negatively impacted [4] staffing levels in the eldercare sector,
\end{abstract}


with musculoskeletal pain as a major contributing factor $[2,5]$. Eldercare employees are disproportionately impacted in comparison to the general working population [2, 5-9]. This is due to the fact that among workers with pain, having manual work is a risk factor for taking sick leave [10]. However, the role of eldercare managers in assisting their employees with musculoskeletal pain to maintain their employment has not been well explored.

The prevalence of musculoskeletal pain in eldercare employees in Denmark is high, with four-weekly prevalence of low back pain (LBP) and neck-shoulder pain (NSP) reported at $61 \%$ and $72 \%$ [11].

However, despite the high levels of musculoskeletal pain, some eldercare employees are able to maintain employment [11]. For instance, Hansen and Andersen (2008) reported that more than $70 \%$ of the employees in Denmark have continued to work despite musculoskeletal pain or being ill over a 12 month period [12]. Additionally, a recent study from 2019 investigating patterns in the occurrence and duration of musculoskeletal pain and interference with work among eldercare workers, found a high one-year prevalence of pain-related work interference among eldercare employees (88\%). This result shows that in spite of the experience of painrelated work interference on the majority of days, this has not been bothersome enough to take sick leave [11]. An explanation for this, could be the extensive focus in Denmark on reducing sickness absence (in particular in the public sector of eldercare work) and having appropriate accommodations to ensure good person-environment fit and maintain the ability to go to work despite of not being $100 \%$ fit/healthy.

For employees with musculoskeletal pain, having supportive management plays a central role in the maintenance of employment [12, 13], but the managers' knowledge and competencies in the utilization of contemporary pain management strategies may be limited $[11,14-16]$.

Managers are in a position to create a work environment that enables employees to remain at work with musculoskeletal pain, through the communication of relevant resources and the provision of accommodations to ensure work tasks are appropriate for individuals' capacities [15]. Organizational culture and managers who are responsive to employees' needs have been identified as important characteristics in enabling employees to stay at work with musculoskeletal pain [17]. Managers who encourage employees to disclose their conditions and capacities for work are then in a position to facilitate appropriate working conditions, and create sustainable employment pathways for their staff despite their musculoskeletal pain [14]. Furthermore, an open relationship has been found to reduce the need for employees to take sick leave $[12,13]$, as they are able to discuss their condition without fear of adverse consequences [18-20]. Managers who endorse open communication are also able to fully utilize organizational policies to support their employees and optimize working conditions [16].

Many gaps remain in the knowledge of how managers can positively influence the working conditions of their employees with musculoskeletal pain and reduce sickness absence. To address these gaps, the overall aim of this study is to investigate the association of managers' knowledge and behaviors in relation to employees' pain and their future risk of musculoskeletal pain and painrelated sickness absence.

\section{Methods}

We used data from the 'Danish Observational Study of Eldercare work and musculoskeletal disorderS' (DOSES). DOSES is a prospective workplace observational study designed to examine the associations between the physical and psychosocial working conditions, musculoskeletal pain and its consequences among eldercare employees in Danish nursing homes. For the current analysis, we used the study's baseline and follow-up data over 1 year. A detailed description of the cohort is provided elsewhere [21].

\section{Study population}

Study participants were 553 Danish eldercare employees, 18-65 years of age and working $15 \mathrm{~h}$ or more on day and evening shifts (employees only working night shifts were excluded), with a minimum of $25 \%$ of their time spent on direct resident care. Participants were recruited from 20 nursing homes and employed as care helpers (14 months of training in care provision, $n=262$ ) or as care aides (additional 6 months of training, $n=215$ ) [21]. For inclusion in this study, participants also had to provide baseline data on musculoskeletal pain and undertake a health check.

\section{Data collection}

From 20 nursing homes, the team managers $(n=42)$ from every ward included in the study responded to a survey about formal and informal structures at the nursing home and wards. Eldercare employees $(n=553)$ were provided with a computer based structured questionnaire that was completed at baseline during a $45-\mathrm{min}$ health check at their respective workplaces. The questionnaire included information about sociodemographics, lifestyle, health and work-related factors (for more information about the questionnaire, see the protocol paper [21]). Support was available to assist with any comprehension issues. For the current study, the questions/ data used are specified in the methods section. 
Managers' knowledge and behaviours were reported by the team managers at baseline using seven items with response categories on a Likert scale ranging from 0 (strongly disagree) to 10 (strongly agree)]. The items were developed for this study and are presented in Table 1 (see also Supplementary material).

\section{Employees' musculoskeletal pain and sickness absence}

Outcome measures for this study were reported by the eldercare employees and collected via text messages on participants' mobile phones (SMS delivered by the SMS Track $^{\circledR}$ system (a Danish commercial system, http:// www.sms-track.com/Default.aspx)). Measures included self-reported pain-related sickness absence in the previous 12 weeks (days) [22], the number of days with low back pain (LBP) in the previous four weeks and the number of days with neck/shoulder pain (NSP) in the previous four weeks measured by a slightly modified Nordic Musculoskeletal Questionnaire (NMQ) [23] (see Supplementary material). The validity and reliability of NMQ has been found to be acceptable and the NMQ has also been used extensively throughout the world and is simple to administer and well accepted by workers [24]. Sickness absence was recorded 5 times (12 weeks apart) over the 1 year follow-up period and musculoskeletal pain questions were recorded 14 times (4 weeks apart) over the same 1 year follow-up period. Figure 1 shows the data collection levels and time points.

Analyses were conducted using three further outcomes: LBP intensity $(0-10)$, NSP intensity $(0-10)$ [23] and total sickness absence in the previous 12 weeks (no. of days) [22]. Pain intensity scales were linked to the 'number of days with pain' questions. For example, if a participant reporting at least one day of LBP, they immediately received a SMS asking about their LBP intensity. Similarly for sickness absence, participants were sent an SMS asking about their total sickness absence and, if they reported at least 1 day with sickness absence, they received another SMS asking about their sickness absence due to musculoskeletal pain.

\section{Demographics}

Demographic information was collected from participants via a baseline questionnaire. For the eldercare employees, we included sociodemographic information (i.e., age, sex), work-related characteristics (i.e. type of job and type of ward), and health and lifestyle (i.e., general health [25], LBP and NSP [23], pain-related sickness absence[22], body mass index (BMI) and smoking). For the managers, we included demographic information (age) and work-related characteristics (i.e. seniority, educational level).

\section{Statistical analyses}

This analysis consisted of two parts. First, we analysed the questions that were asked to managers with the aim of grouping the questions into common themes/concepts that would be useful to understand in relation to worker health. We then took those concepts (or 'factors') and used regression modelling to determine how those concepts related to pain and sickness absence among workers.

\section{Managers' knowledge and behaviours}

To identify relevant subscales from the seven items, we conducted an exploratory factor analysis, using principal components analysis with varimax rotation, using IBM SPSS Statistics for Windows, version 25.0 [26].

\section{The association between managers' knowledge and behaviours on musculoskeletal pain and sickness absence among the employees}

To investigate associations between the knowledge and behaviours reported by managers on musculoskeletal pain and pain-related sickness absence among eldercare employees, we used quasi-Poisson, mixed-effects regression modelling. To select the most appropriate regression model, we first assessed the type and distribution of the data which suggested a Poisson, quasi-Poisson or negative-binomial model. The most appropriate model was selected based on QQplots of the observed versus

Table 1 Managers'knowledge and behaviors items

Managers' knowledge and behaviors items

\footnotetext{
"I am sure that I have enough information to help employees prevent and manage pain"

"There are things I do regularly to prevent pain among employees"

"I help clarify what options my employees have to prevent and manage pain"

"When employees have pain, I really understand how they feel"

"I am doing something active when my employees do pay attention to their pain"

"I help my employees to find out what measures they are entitled to if they have pain"

"It is easy to find solutions at work, if my employees have pain"
} 


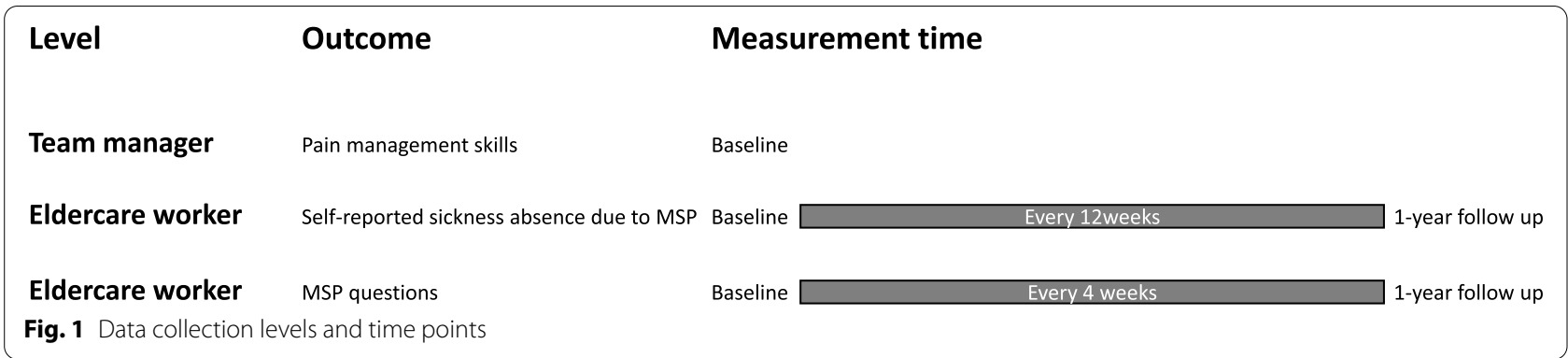

expected residuals and Akaike information criterion (AIC) values.

Two models were constructed for each outcome. The first model included all constructs identified in the factor analysis as fixed effects. The second model included all constructs as per model 1 plus terms for the interactions between each construct. In all models, we included the nursing home, ward and individual as hierarchical levels (individuals nested within wards, wards nested within nursing homes) with random intercepts to account for any potential grouping effects of these levels. All regression analyses were conducted using $\mathrm{R}$ and RStudio, along with Packages tidyverse [27], glmmTMB [28], broom. mixed [29], DHARMa [30] and effects [31].

\section{Results}

\section{Managers' knowledge and behaviours}

A total of 42 managers were included in this study, with a mean age of 48 years, with average experience in their current position for 4 years and 10 years of experience as a manager. Thirty-eight percent of managers had never worked as a care employee, and $38 \%$ had management training. See Table 2.

Table 2 Demographic and descriptive statistics for the managers

\begin{tabular}{ll}
\hline & $\begin{array}{l}\text { Mean (SD), } \boldsymbol{n} \text { (\%) } \\
\text { or median (IQR) }\end{array}$ \\
\hline Age & $48.9($ SD 7.2) \\
Time in current position (years) & $4.5($ IQR 1.4 to 6.2) \\
Total time in management positions (years) & 10.7 (IQR 6.0 to 15.0) \\
Time spent as a care employee & \\
$\quad$ Former & $18(43 \%)$ \\
Concurrent & $8(19 \%)$ \\
$\quad$ None & $16(38 \%)$ \\
Education level & \\
$\quad$ Qualification + additional management training & $16(38 \%)$ \\
Qualification as a Nurse & $11(26 \%)$ \\
Qualification as a Care Aide & $10(24 \%)$ \\
Other & $5(12 \%)$
\end{tabular}

Data are mean or numbers

$S D$ standard deviation, IQR interquartile range
A component structure with four factors (two with single items) was identified as optimal after examination of the scree plot and taking factor interpretability into account (see figure $\mathrm{A}$ in Appendix). This solution accounted for $85 \%$ of the variance in managers' knowledge and behaviours (see table A Appendix). Factor loadings and Cronbach's alpha are presented in table B Appendix. Constructs were named according to the major theme of the item/s:

1. Prevention ( $\mathbf{3}$ items) - actions taken by the manager for the prevention of musculoskeletal pain.

2. Pain management ( 2 items) - actions taken by the manager to assist employees with musculoskeletal pain.

3. Entitlements (single item) - managers' ability to communicate on entitlements for employees with musculoskeletal pain.

4. Workplace accommodations (single item) - managers' ability to find accommodations for employees with musculoskeletal pain.

\section{Eldercare employees' characteristics}

A total of 535 eldercare employees were included, with an average age of 45 years and mostly women (95\%). Care aides $(46 \%)$ or care helpers $(44 \%)$ were the most common roles, in somatic wards (75\%). Employees were on average slightly overweight $(\mathrm{BMI}=26.6)$ and $36 \%$ were current smokers. More than $80 \%$ reported good, very good or excellent health. Median number of days recorded with LBP and NSP per month was 4 . See Table 3.

\footnotetext{
Managers' knowledge and behaviours and the association with employees' musculoskeletal pain and sickness absence

Model 1 (no interaction effects) showed no statistically significant associations between managers' knowledge and behaviours and employees' musculoskeletal pain (LBP or NSP) or sickness absence due to musculoskeletal pain. Coefficients ranged from -0.08 to 0.09 . The
} 
Table 3 Demographic, work-related, health and lifestyle descriptive statistics for the eldercare employees

\begin{tabular}{|c|c|}
\hline & $\begin{array}{l}\text { Mean (SD), } n(\%) \\
\text { or median (IQR) }\end{array}$ \\
\hline Age (years; $n=535$ ) & $45.3(10.8)$ \\
\hline Sex (female; $n=535$ ) & $510(95 \%)$ \\
\hline \multicolumn{2}{|l|}{$\mathrm{Job}(n=521)$} \\
\hline Care aide & $241(46 \%)$ \\
\hline Care helper & $227(44 \%)$ \\
\hline Nurse or other health professional & $53(10 \%)$ \\
\hline \multicolumn{2}{|l|}{ Type of Ward $(n=535)$} \\
\hline Somatic & $401(75 \%)$ \\
\hline Dementia & $110(21 \%)$ \\
\hline Temporary rehabilitation & $15(3 \%)$ \\
\hline Independent living & $9(2 \%)$ \\
\hline $\mathrm{BMI}(n=489)$ & $26.6(5.3)$ \\
\hline \multicolumn{2}{|l|}{ Self-rated health $(n=524)$} \\
\hline Excellent & $17(3 \%)$ \\
\hline Very good & $140(27 \%)$ \\
\hline Good & $282(54 \%)$ \\
\hline Not so good & $78(15 \%)$ \\
\hline Poor & $7(1 \%)$ \\
\hline \multicolumn{2}{|l|}{ Smoking $(n=525)$} \\
\hline Current smoker & $187(36 \%)$ \\
\hline Former smoker & $159(30 \%)$ \\
\hline Never smoked & $179(34 \%)$ \\
\hline Days with low back pain ( $0-28$ days; $\left.n=6267^{*}\right)$ & 4 (IQR 0 to 10$)$ \\
\hline Days with neck/shoulder pain (0-28 days; $\left.n=6273^{*}\right)$ & 4 (IQR 0 to 11) \\
\hline Days with pain-related sickness absence ( $0-84$ days; $\left.n=2191^{*}\right)$ & $0($ IQR 0 to 0$)$ \\
\hline Responses with at least 1 day of sickness absence due to musculoskeletal pain & $265(12 \%)$ \\
\hline
\end{tabular}

Data are mean, numbers or median

$B M I$ Body Mass Index, SD standard deviation, $I Q R$ interquartile range

$n$ for these values is the number of data points (i.e., the sample population $\mathrm{x}$ the number of times they responded to the question)

marginal $R^{2}\left(R_{m}^{2}\right)$ for all three outcomes (LBP, NSP and sickness absence due to musculoskeletal pain) was 0.01 . Full results are available in Table 4.

In model 2 (including interaction effects), we identified statistically significant associations between the employees of managers who scored higher on pain management and more low back pain $(\beta=0.57$; $95 \% \mathrm{CI}=[0.02 ; 1.11])$. Fewer days of pain-related sickness absence were reported by employees of managers who reported being able to explain entitlements than by employees whose managers reported they were not able to explain entitlements $(-0.62[-1.14 ;-0.10])$.

We found significant interaction effects between preventive actions and pain management $(-0.11$ [ -0.21 ; $-0.01])$, preventive actions and workplace accommodations $(0.06[0.00 ; 0.11])$, and explanations of entitlements and workplace accommodations (0.05 [0.00; 0.09]).

Full results are available in Table 4 and Figs. 2a-c.

\section{Sensitivity analyses}

In model 1 (no interaction effects) there were no statistically significant associations between managers' knowledge and behaviours and employees' pain intensity (LBP or NSP), or total sickness absence. For model 2 (including interaction effects) statistically significant associations were identified for total sickness absence with a statistically significant interaction effect for preventive actions times workplace accommodations $(0.03[0,00 ; 0.06])$. Full results are available in Table $\mathrm{C}$ in Appendix.

\section{Discussion}

We investigated the association between managers' knowledge and behaviors towards employees' pain and the future risk of musculoskeletal pain and painrelated sickness absence among employees. Four types of managers' knowledge and behaviors were identified: 1) Pain-prevention (actions for prevention of employee pain), 2) Pain-management (actions to assist employees 
Table 4 Multivariate analyses for the association between managers' knowledge and behaviours and musculoskeletal pain and painrelated sickness absence among eldercare employees

\begin{tabular}{|c|c|c|c|}
\hline & Days with LBP & Days with NSP & $\begin{array}{l}\text { Sickness absence } \\
\text { due to MSP }\end{array}$ \\
\hline \multicolumn{4}{|l|}{ Model 1 (no interaction effects) } \\
\hline$R_{m}^{2}$ & 0.01 & 0.01 & 0.01 \\
\hline Pain-prevention & $\begin{array}{l}-0.04 \\
{[-0.12 ; 0.05]}\end{array}$ & $\begin{array}{l}0.00 \\
{[-0.08 ; 0.08]}\end{array}$ & $\begin{array}{l}0.01 \\
{[-0.10 ; 0.12]}\end{array}$ \\
\hline Pain-management & $\begin{array}{l}0.09 \\
{[-0.03 ; 0.21]}\end{array}$ & $\begin{array}{l}0.03 \\
{[-0.07 ; 0.13]}\end{array}$ & $\begin{array}{l}-0.08 \\
{[-0.22 ; 0.06]}\end{array}$ \\
\hline Pain-entitlements & $\begin{array}{l}-0.02 \\
{[-0.10 ; 0.05]}\end{array}$ & $\begin{array}{l}-0.05 \\
{[-0.11 ; 0.02]}\end{array}$ & $\begin{array}{l}-0.02 \\
{[-0.12 ; 0.07]}\end{array}$ \\
\hline Pain-accommodations & $\begin{array}{l}0.00 \\
{[-0.07 ; 0.07]}\end{array}$ & $\begin{array}{l}0.01 \\
{[-0.04 ; 0.06]}\end{array}$ & $\begin{array}{l}0.01 \\
{[-0.07 ; 0.09]}\end{array}$ \\
\hline \multicolumn{4}{|l|}{ Model 2 (interaction effects included) } \\
\hline$R_{m}^{2}$ & 0.02 & 0.01 & 0.09 \\
\hline Pain-prevention & $\begin{array}{l}0.12 \\
{[-0.53 ; 0.78]}\end{array}$ & $\begin{array}{l}-0.22 \\
{[-0.78 ; 0.34]}\end{array}$ & $\begin{array}{l}0.68 \\
{[-0.12 ; 1.47]}\end{array}$ \\
\hline Pain-management & $\begin{array}{l}0.57 \\
{[0.02 ; 1.11]}\end{array}$ & $\begin{array}{l}0.07 \\
{[-0.41 ; 0.56]}\end{array}$ & $\begin{array}{l}0.45 \\
{[-0.23 ; 1.13]}\end{array}$ \\
\hline Pain-entitlements & $\begin{array}{l}0.23 \\
{[-0.18 ; 0.64]}\end{array}$ & $\begin{array}{l}0.01 \\
{[-0.34 ; 0.36]}\end{array}$ & $\begin{array}{l}-0.62 \\
{[-1.14 ;-0.10]}\end{array}$ \\
\hline Pain-accommodations & $\begin{array}{l}0.19 \\
{[-0.36 ; 0.74]}\end{array}$ & $\begin{array}{l}0.11 \\
{[-0.31 ; 0.53]}\end{array}$ & $\begin{array}{l}-0.19 \\
{[-0.80 ; 0.41]}\end{array}$ \\
\hline Pain-prevention:Pain-management & $\begin{array}{l}-0.02 \\
{[-0.10 ; 0.06]}\end{array}$ & $\begin{array}{l}0.02 \\
{[-0.05 ; 0.09]}\end{array}$ & $\begin{array}{l}-0.11 \\
{[-0.21 ;-0.01]}\end{array}$ \\
\hline Pain-prevention:Pain-entitlements & $\begin{array}{l}-0.02 \\
{[-0.07 ; 0.03]}\end{array}$ & $\begin{array}{l}0.00 \\
{[-0.04 ; 0.04]}\end{array}$ & $\begin{array}{l}-0.02 \\
{[-0.08 ; 0.05]}\end{array}$ \\
\hline Pain-prevention:Pain- accommodations & $\begin{array}{l}0.03 \\
{[-0.02 ; 0.07]}\end{array}$ & $\begin{array}{l}0.00 \\
{[-0.03 ; 0.04]}\end{array}$ & $\begin{array}{l}0.06 \\
{[0.00 ; 0.11]}\end{array}$ \\
\hline Pain-management: Pain-entitlements & $\begin{array}{l}-0.02 \\
{[-0.06 ; 0.03]}\end{array}$ & $\begin{array}{l}-0.01 \\
{[-0.05 ; 0.03]}\end{array}$ & $\begin{array}{l}0.05 \\
{[-0.01 ; 0.12]}\end{array}$ \\
\hline Pain-management: Pain-accommodations & $\begin{array}{l}-0.03 \\
{[-0.10 ; 0.03]}\end{array}$ & $\begin{array}{l}-0.01 \\
{[-0.07 ; 0.04]}\end{array}$ & $\begin{array}{l}-0.06 \\
{[-0.14 ; 0.02]}\end{array}$ \\
\hline Pain-entitlements: Pain-accommodations & $\begin{array}{l}-0.01 \\
{[-0.04 ; 0.03]}\end{array}$ & $\begin{array}{l}0.00 \\
{[-0.03 ; 0.03]}\end{array}$ & $\begin{array}{l}0.05 \\
{[0.00 ; 0.09]}\end{array}$ \\
\hline
\end{tabular}

LBP Low back pain

NSP Neck/shoulder pain

MSP musculoskeletal pain

$R_{m}^{2}$ Marginal $R^{2}$ (the variance explained by the fixed effects in the model)

manage their pain), 3) Pain-entitlements (communicating entitlements to assist employees with pain), and 4) Pain-accommodations (ability to facilitate workplace accommodations for employees with pain).

Employees of managers who scored higher in the area of knowledge of pain-entitlements had fewer days of pain-related sickness absence and employees of managers who scored higher on knowledge of pain-management had more low back pain. Direct relationships between the other knowledge and behaviors measures and musculoskeletal pain and pain-related sickness absence were not statistically significant. That is probably due to limited statistical power for interaction analyses. However, when we examined the influence of interactions between the different managers' knowledge and behaviors, we found several key associations between the knowledge and behaviors measures and pain-related sickness absence. This likely reflects the complexity of pain management and the need for a nuanced and multifactorial approach to assist employees in managing their musculoskeletal pain at work. In the following sections we discuss the findings and their practical implications.

\section{Pain-related sickness absence}

As we had expected, we found an association between managers' knowledge and behaviors and employees' future risk of pain-related sickness absence. The 


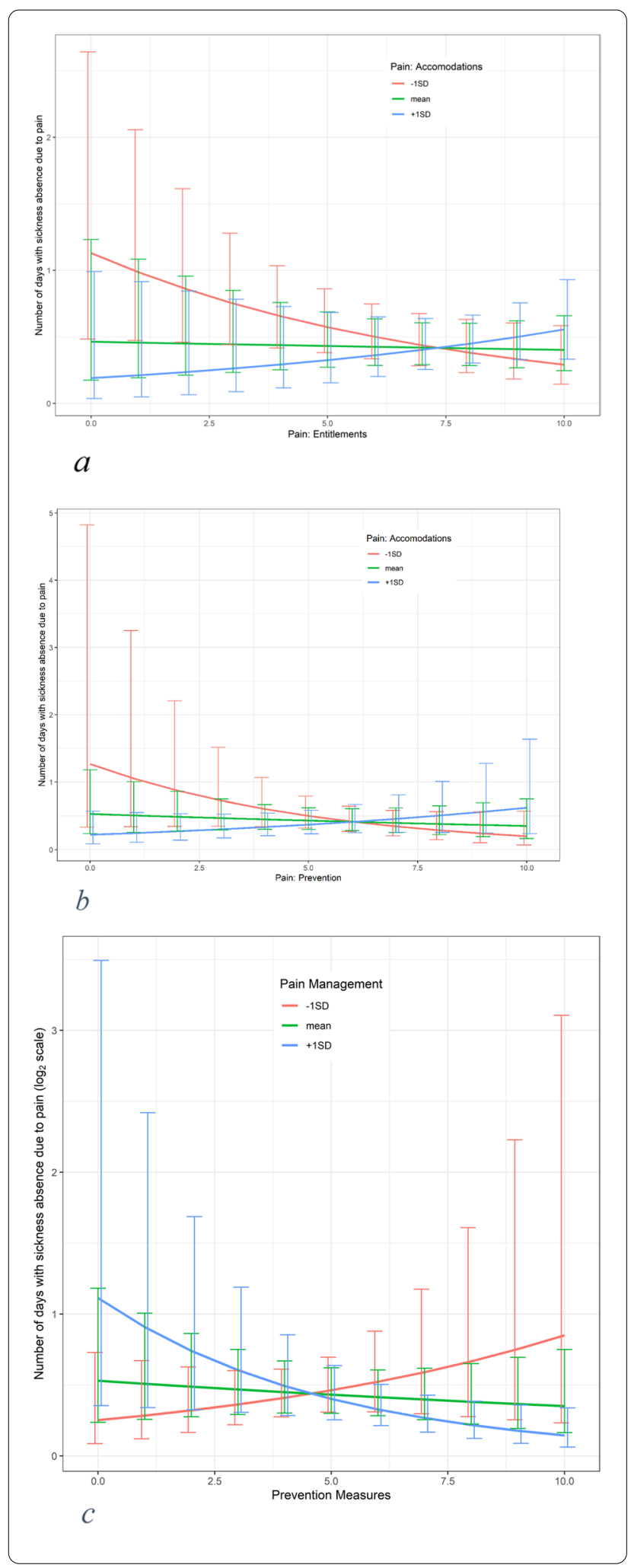

Fig. 2 a Interaction between pain-entitlements and pain-accommodations on the associations with pain-related sickness absence. $\mathbf{b}$ Interaction between pain-prevention and pain-accommodations on the associations with pain-related sickness absence. $\mathbf{c}$ Interaction between pain-prevention and pain-management on the associations with pain-related sickness absence

employees of managers who scored higher on knowledge of pain-entitlements had fewer days of pain-related sickness absence. This association was particularly pronounced with managers who reported lower scores on pain-accommodation compared to those with higher scores. In other words, when managers' were not as proficient in their ability to communicate the range of entitlements available to assist employees in managing their musculoskeletal pain, or potential workplace accommodations for employees, sickness absence was higher (more days). The association between entitlements and pain-related sickness absence was also stronger when the managers reported lower knowledge of pain-prevention. Thus, ensuring that managers are well versed in the availability of entitlements for their employees and then encouraging them to communicate this information and to take preventative actions may offer opportunities for organisations to reduce absenteeism and reap economic benefits due to improved staff retention [17].

Finally, the association between managers' pain-prevention and employee pain-related sickness absence depended on the managers skills with pain-management. Here we found that when managers reported higher knowledge of pain-management (i.e. actions taken by the manager to assist employees with musculoskeletal pain), lower scores on knowledge of pain-prevention (i.e. actions taken by the manager for the prevention of musculoskeletal pain) were associated with more sickness absence days among their employees.

These results indicate that knowledge of preventive actions for employee pain among the managers is an important factor for assisting employees with musculoskeletal pain. This is in line with findings from a previous study in eldercare workers, that found that managers' handling of employees with pain among others depend on employee handling of-and communication aboutpain, managers' perception of their role towards employees with pain and procedures and informal approaches for handling employees with pain [14].

Overall, these findings support the need for a multifaceted approach to ensure that managers have the appropriate information to share with their employees and then the ability to develop and provide appropriate accommodations and actions to meet the capacities of employees with musculoskeletal pain. 


\section{Musculoskeletal pain}

The employees of managers who scored higher on painmanagement had more low back pain. This may reflect the wording of the questions. Pain management, was covered by two questions: "When employees have pain, I really understand how they feel" and "I am doing something active when my employees have pain". This may reflect that a proactive focus on pain from managers, will increase pain reporting among employees. Whilst the findings may appear contradictory to expectations, closer examination of the items, demonstrates their relationship to understanding of an employee's pain and then provision of active support in staying at work. Previous research supports the need for open disclosure by employees with musculoskeletal pain to their managers $[12,13]$, stating that such interventions may not be effective at reducing pain levels but have other work related benefits [12]. Open disclosure is consistent with a biopsychosocial approach to pain management where minimisation of the pain is not the primary focus but enabling individuals to participate in meaningful work is important $[32,33]$. The ability to discuss musculoskeletal pain conditions with a supervisor or manager enables the implementation of appropriate workplace accommodations which enable employees to stay at work and reduce associated sickness absence. Overall, the findings from the current study support previous research which has identified the importance of managers in assisting employees with musculoskeletal pain to maintain employment [14, $15,34,35]$.

\section{Strengths and limitations}

A major strength of this study is the multilevel approach utilised for data collection and analysis. A further strength is that pain management actions of managers was not reported by the employees, but by the managers themselves. A potential limitation of this study is that (although identifying specific causal mechanisms is beyond the scope of this study) reverse causality is an issue. As such we cannot be sure whether worker health changes as a result of managers' knowledge and behaviours, or the other way around. However, the potential impact of this issue is reduced through the prospective nature of the analysis. Another potential limitation relates to the use of self-reported sickness absence and the inability to discriminate short-term and longterm sickness absence.

\section{Future research}

The novel and exploratory nature of our study means that replication of these findings in other studies is required. An important question is whether these findings are true for this job group only, or for other occupations, cultures and countries as well. A need exists for testing interventions for training managers in knowledge and behaviours, such as in the knowledge and then communication of entitlements and the relevant organizational processes to support those employees with musculoskeletal pain and the subsequent impact on sickness absence. Also, guidelines/tools are needed to support the managers in their roles. Finally, the knowledge and behaviours measures utilised here could be inlcluded as part of a process evaluations for interventions to support pain management by managers.

\section{Conclusion}

Managers' knowledge and behaviors towards employees' pain were associated with employees' future musculoskeletal pain and sickness absence. The complex relationships between knowledge and behaviours suggests that a multifaceted approach is needed to ensure that managers have the appropriate information to share with their employees and then have the ability to develop and provide appropriate accommodations and actions to meet the capacities of employees with musculoskeletal pain. Training of managers in contemporary pain management practices, including explanation of entitlements and the organisational process to support employees in remaining at work, may help to address the ongoing challenges with staffing in eldercare.

\section{Abbreviations \\ AIC: Akaike information criterion; BMI: Body mass index; Cl: Confidence inter- val; DOSES: Danish Observational Study of Eldercare work and musculoskeletal disorders; IQR: Interquartile range; LBP: Low back pain; NMQ: Nordic Musculo- skeletal Questionnaire; NSP: Neck shoulder pain; SD: Standard deviation.}

\section{Supplementary Information}

The online version contains supplementary material available at https://doi. org/10.1186/s12889-022-12785-x.

Additional file 1.

Additional file 2: Appendix.

Acknowledgements

The authors wish to thank the entire DOSES research group and personnel who contributed to the data collection, and the 20 nursing homes that participated in DOSES.

Authors' contributions

JO and MWS was responsible for the analysis of the data. CNR, JO, MWS and $\mathrm{AHO}$ was responsible for interpretation of data and CNR was responsible for writing of the manuscript. $\mathrm{AHO}, \mathrm{KKA}$ and RER was involved in proposal writing, and interpretation of results. All authors have read and approved the final manuscript. 


\section{Funding}

The study was financed by a grant from the Danish government and by a grant from the Danish Work Environment Research Fund (grant no. 22-2019-09).

\section{Availability of data and materials}

The datasets generated during and analysed during the current study are not publicly available but are available from the corresponding author on reasonable request.

\section{Declarations}

\section{Ethics approval and consent to participate}

This study was approved by the Danish Data Protection Agency and the Ethics Committee for the regional capital of Denmark (reference number $\mathrm{H}-4-2013-028$ ) and have therefore been performed in accordance with the ethical standards laid down in the 1964 Declaration of Helsinki and its later amendments. All participants gave their written informed consent prior to their inclusion in the study.

\section{Consent for publication}

Not applicable.

\section{Competing interests}

The authors declare that they have no competing interests.

\section{Author details}

${ }^{1}$ National Research Centre for the Working Environment, Copenhagen, Denmark. ${ }^{2}$ Centre for Ergonomics and Human Factors, School of Psychology and Public Health, LaTrobe University, Melbourne, Australia. ${ }^{3}$ Department of Public Health, University of Copenhagen, Copenhagen, Denmark. ${ }^{4}$ Department of Psychology, University of Copenhagen, Copenhagen, Denmark.

Received: 25 April 2021 Accepted: 16 February 2022

Published online: 04 March 2022

\section{References}

1. Campbell JDG, Buchan J, Pozo-Martin F, Guerra Arias M, Leone C, Siyam A, Cometto G. A Universal Truth: No Health Without a Workforce. Geneva: Global Health Workforce Alliance and World Health Organization; 2013.

2 Andersen LL, Clausen T, Mortensen OS, Burr H, Holtermann A. A prospective cohort study on musculoskeletal risk factors for long-term sickness absence among healthcare workers in eldercare. International archives of occupational environmental health. 2012;85(6):615-22.

3. Stapelfeldt CM, Jensen C, Andersen NT, Fleten N, Nielsen CVJBph: Validation of sick leave measures: self-reported sick leave and sickness benefit data from a Danish national register compared to multiple workplaceregistered sick leave spells in a Danish municipality. BMC Public Health. 2012;12(1):661.

4. Stapelfeldt CM, Nielsen CV, Andersen NT, et al. Sick leave patterns as predictors of disability pension or long-term sick leave: a 6.75-year follow-up study in municipal eldercare workers. BMJ Open. 2014;4:e003941. https:// doi.org/10.1136/bmjopen-2013-003941.

5. Jensen LD, Ryom PK, Christensen MV, et al. Differences in risk factors for voluntary early retirement and disability pension: a 15-year follow-up in a cohort of nurses' aides. BMJ Open. 2012;2:e000991. https://doi.org/10. 1136/bmjopen-2012-000991.

6. Bevan S, Quadrello T, McGee R, Mahdon M, Vavrovsky A, Barham L 2009 Fit for work. In: Musculoskeletal disorders in the European workforce. Volume 2009, edn. London: The work foundation

7. Vos T, Barber RM, Bell B, Bertozzi-Villa A, Biryukov S, Bolliger I, Charlson F, Davis A, Degenhardt L, Dicker D. Global, regional, and national incidence, prevalence, and years lived with disability for 301 acute and chronic diseases and injuries in 188 countries, 1990-2013: a systematic analysis for the Global Burden of Disease Study 2013. The Lancet. 2015;386(9995):743-800.

8. Davis KG, Kotowski SE. Prevalence of musculoskeletal disorders for nurses in hospitals, long-term care facilities, and home health care: a comprehensive review. Hum Factors. 2015;57(5):754-92.
9. Mäntyselkä PT, Kumpusalo EA, Ahonen RS, Takala J. Direct and indirect costs of managing patients with musculoskeletal pain-challenge for health care. Eur J Pain. 2002;6(2):141-8.

10. Hallman DM, Holtermann A, Björklund M, Gupta N, Rasmussen CDN. Sick leave due to musculoskeletal pain: determinants of distinct trajectories over 1 year. Int Arch Occup Environ Health. 2019;92(8):1099-108.

11. Rasmussen CDN, Larsen AK, Holtermann A, Søgaard K, Jørgensen MB. Adoption of workplaces and reach of employees for a multi-faceted intervention targeting low back pain among nurses' aides. BMC Med Res Methodol. 2014;14(1):60.

12. Oakman J, Keegel T, Kinsman N, Briggs AM. Persistent musculoskeletal pain and productive employment; a systematic review of interventions. Occup Environ Med. 2016;73(3):206-14.

13. de Vries HJ, Reneman MF, Groothoff JW, Geertzen JH, Brouwer SJ. Factors promoting staying at work in people with chronic nonspecific musculoskeletal pain: a systematic review. Disabil Rehabil. 2012;34(6):443-58.

14. Larsen AK, Falkenstrøm S, Jørgensen MB, Rod MH. The role of managers in addressing employees with musculoskeletal pain: a mixed methods study. Int Arch Occup Environ Health. 2018;91(3):361-72.

15. Linton SJ, Boersma K, Traczyk M, Shaw W, Nicholas M. Early workplace communication and problem solving to prevent back disability: results of a randomized controlled trial among high-risk workers and their supervisors. J Occup Rehabil. 2016;26(2):150-9.

16. Cunningham C, Doody C, Blake C. Managing low back pain: knowledge and attitudes of hospital managers. Occup Med. 2008;58(4):282-8.

17. Oakman J, Kinsman N, Briggs AM. Working with persistent pain: an exploration of strategies utilised to stay productive at work. J Occup Rehabil. 2017;27(1):4-14.

18. Dellve L, Skagert K, Vilhelmsson R. Leadership in workplace health promotion projects: 1-and 2-year effects on long-term work attendance. Eur J Public Health. 2007;17(5):471-6.

19. Sterud T, Johannessen HA. Tynes TJlaoo: Work-related psychosocial and mechanical risk factors for neck/shoulder pain: a 3-year follow-up study of the general working population in Norway. Int Arch Occup Environ Health. 2014;87(5):471-81.

20. Wynne-Jones G, Buck R, Porteous C, Cooper L, Button LA, Main CJ, Phillips C. What happens to work if you're unwell? Beliefs and attitudes of managers and employees with musculoskeletal pain in a public sector setting. J Occup Rehabil. 2011;21(1):31-42.

21. Karstad K, Jørgensen AF, Greiner BA, Burdorf A, Søgaard K, Rugulies R, Holtermann A: Danish observational study of eldercare work and musculoskeletal disorderS (doses): a prospective study at 20 nursing homes in Denmark. BMJ Open. 2018;8:e019670. https://doi.org/10.1136/bmjop en-2017-019670.

22. Gabel CP, Melloh M, Burkett B, Osborne J, Yelland M. The Örebro Musculoskeletal Screening Questionnaire: validation of a modified primary care musculoskeletal screening tool in an acute work injured population. Man Ther. 2012;17(6):554-65.

23. Kuorinka I, Jonsson B, Kilbom A, Vinterberg H, Biering-Sørensen F, Andersson G, Jørgensen K. Standardised Nordic questionnaires for the analysis of musculoskeletal symptoms. Appl Ergon. 1987;18(3):233-7.

24. Baron S, Hales T, Hurrell J. Evaluation of symptom surveys for occupational musculoskeletal disorders. American J Ind Med. 1996;29(6):609-17.

25. Bjorner JB, Thunedborg K, Kristensen TS, Modvig J, Bech P. The Danish SF-36 Health Survey: translation and preliminary validity studies. J Clin Epidemiol. 1998;51(11):991-9.

26. Corp. I. IBM SPSS Statistics for Windows Version 25.0. In: Armonk. NY: IBM Corp; 2017. (Released 2017).

27. Wickham H, Averick M, Bryan J, Chang W, McGowan LDA, François R, Grolemund G, Hayes A, Henry L, Hester J. Welcome to the Tidyverse. Journal of open Source Software. 2019;4(43):1686.

28. Brooks ME, Kristensen K, van Benthem KJ, Magnusson A, Berg CW, Nielsen A, Skaug HJ, Machler M, Bolker BM. glmmTMB balances speed and flexibility among packages for zero-inflated generalized linear mixed modeling. The R journal. 2017;9(2):378-400.

29. Bolker B, Robinson D. Broom. mixed: Tidying methods for mixed models. R package version. 2019;667(0.2):4.

30. Hartig F: DHARMa: residual diagnostics for hierarchical (multi-level/ mixed) regression models. R package version 01. 2017;5(5). 
31. Fox J, Hong J. Effect displays in R for multinomial and proportionalodds logit models: Extensions to the effects package. J Stat Softw. 2009;32(1):1-24.

32. Speerin R, Slater H, Li L, Moore K, Chan M, Dreinhöfer K, Ebeling PR, Willcock S, Briggs AM. Moving from evidence to practice: models of care for the prevention and management of musculoskeletal conditions. Best Practice Res Clin Rheumatol. 2014;28(3):479-515.

33. Hayes $\mathrm{C}$, Hodson FJJ. A whole-person model of care for persistent pain: from conceptual framework to practical application. Pain Med. 2011;12(12):1738-49.

34. O'Donnell EM, Berkman LF, Subramanian S. Manager support for work/family issues and its impact on employee-reported pain in the extended care setting. Journal of occupational environmental medicine. 2012;54(9):1142.

35. Skakon J, Nielsen K, Borg V, Guzman JJW. stress: Are leaders' wellbeing, behaviours and style associated with the affective well-being of their employees? A systematic review of three decades of research. 2010;24(2):107-39.

\section{Publisher's Note}

Springer Nature remains neutral with regard to jurisdictional claims in published maps and institutional affiliations.

- fast, convenient online submission

- thorough peer review by experienced researchers in your field

- rapid publication on acceptance

- support for research data, including large and complex data types

- gold Open Access which fosters wider collaboration and increased citations

- maximum visibility for your research: over 100M website views per year

At BMC, research is always in progress.

Learn more biomedcentral.com/submissions 